\title{
ACERCA DEL CUERPO Y DE LA DELECTACIÓN SENSIBLE EN ALGUNOS TEXTOS DE LA PRIMERA PARTE DE LA SUMA DE TEOLOGÍA
}

Angel Salvador Astolfo

SINTESIS - La pregunta sobre el significado del cuerpo y de la delectación sensible corresponde de hecho a la problemática de nuestro siglo. Su consideración en los autores medievales exige una contextualización previa, en especial en el caso de la Suma de Teologia por la importancia del "ordo disciplinae". Se hacen notar la importancia de los desarrollos sobre la naturaleza y la psicologia del hombre (q. 74-89) centrando el studio de detalle en las cuestiones relativas al origen del hombre (q. 90-102). Se indaga sobre el significado del cuerpo en su producción, en la "imagem de Dios" y en la condición corporca en el estado de justicia original. Estas perspectivas sientan las bases para la consideración de la delectación sensible en la la - llae. El texto bíblico tradicional revelará nuevas dimensiones de la realidadgracias al auxilio de una filosofía cuya valoración del orden de las causas es decisivo. Los dos co-principios serán vistos desde una perspectiva que, sibien se polariza en uno de los términos, no por ello desmerece al outro ni opaca la afirmación clara que el cuerpo es la expresión y realización espacio-temporal del alma. Sintesis auténticamente personal, decisiva, pero indudablemente situada en un contexto donde lo concreto y experiencial no detenta ciertamente la primacía.

PALABRAS-CLAVE - Tomás de Aquino. Suma teologica. Cuerpo. Delectación sensible.
ABSTRACT - The question on the meaning of the body and of the sensitive delectation it corresponds in fact to the problem of our century. Its consideration in the medieval authors demands a previous contextualization, especially in the case of the Sum of Theology for the importance of the "ordo disciplinae". They are made notice the importance of the developments on the and the man's psychology (q. 74 89) centering the detail study in the relative questions to the man's ongin (q. 90-102). One investigates on the meaning of the body in their production, in the "image of God" and in the corporal condition in the state of original justice. These perspective establish the bases for the consideration of the sensitive delectation in the la llae. The traditional biblical text will reveal new dimensions of the reality thanks to the aid of a philosophy whose valuation of the order of the causes is decisive. The two co-principles will be seen from a perspective that, although its polarized, in tact of the terms, not for that it undeserve to the other neither opaque the clear statemente that the body is the expression and realization spatial-temporal of the soul. Genuinely personal, decisive synthesis, but undoubtedly located in a context where the concrete thing and experiencial don't hold the primacy certainly.

KEY WORDS - Thomas Aquinas. Summe of theologie. Body. Sensible delight.

Professor da Universidad Católica de Rosario (Argentina). 
La pregunta sobre el significado teológico del cuerpo y de la delectación sensible nos conduce de lleno al abordaje del misterio del hombre desde su realidad corpórea de modo tal que, el lugar y la valoración que se le otorgue a la corporalidad y a todo lo conexo con ella, caracteriza la reflexión antropológica en todo su ámbito.

La consideración del misterio del hombre desde este punto de vista es relativamente reciente. En antropología teológica hoy, hablar de corporalidad significa superar la clásica discusión sobre la relación entre el alma y el cuerpo desde el punto de vista metafísico, para orientar la reflexión hacia todo aquello que constituye la totalidad del ser hombre y que concierne a la subjetividad humana en su intimidad profunda y en su comportamiento. Estos temas y toda su problemática dependen inmediatamente de las investigaciones de la filosofía fenomenológica y de la renovación de los estudios bíblicos ${ }^{1} y$, mediatamente, de la cosmovisión desarrollada sobre todo a partir del siglo XVIII. ${ }^{2}$

En el siglo XIII la situación es totalmente distinta. La diferencia no estriba en tal o cual elemento particular sino que está constituida por un conjunto religioso, intelectual, social, político y afectivo extremadamente complejo. Más allá del neoplatonismo vehiculado por la tradición patrística, por encima de la subestructura agustiniana de todo el pensamiento medieval, superando las cuestiones planteadas por la recepción más o menos entusiasta de Aristóteles, aparece, en el renacimiento cristiano del siglo XIII, una actitud característica y propia de situar las relaciones entre Dios, el mundo y el hombre. ${ }^{3}$ La traducción fáctica y cotidiana de esta actitud, con todo lo que ello conlleva, origina una mentalidad, una cosmovisión, una síntesis total en cuyo seno se inscriben un universo de matices y por qué no, de divergencias.

La antropología teológica, a partir de su contextualización, es uno de los temas decisivos en este renacimiento cristiano. Cuestiones como la unión del alma y del cuerpo, la validez del conocimiento de la razón y el aporte de los sentidos en dicho conocimiento en orden a las cuestiones decisivas para el hombre en este mundo, constituyen los ejes en tomo a los cuales giraran las discusiones entre el agustinismo y el aristotelismo en sus múltiples facetas.

Esta brevísima reseña nos indica ya cuáles son las posibilidades que enmarcan nuestra preocupación en el contexto del siglo XIII. Desde ya cabe la posibilidad que todo abordaje sobre la corporalidad y el placer sensible sean indirectos y se logren por un camino que tal vez de entrada parezca alejarse demasiado de nuestra preocupación central.

1 M.-D. Chenu, Situation humaine: corporalité et temporalité, en La Parole de Dieu, II. - L'Evangile dans le temps, Cogitatio Fidei, Paris, Cerf, 1964, p. 411.

2 L. Lenoble, L'évolution de l'idée de nature au XVI et au XVIIr siècles, en Revue de Métaphysique et morale, 58(1953) 108-129; sobre la cuestión del método ver p. 108-112. A. Koyré, Del mundo cerrado al universo infinito, Siglo Veintiuno Mexico, 1979.

3 M.-D., Chenu, Introduction à l'étude de saint Thomas d'Aquin.(Institut d' Etudes Médivales, XI), 2. éd. Montréal-Paris1954, p. 22-28. Sobre los origenes de dicho renacimiento, ver M. - D. Chenu, La thélogie au douzième siècle, (Etudes de Philosophie médievale XLV), Paris, Vrin 1957. 
Cabe explicar por qué hemos escogido a Tomás de Aquino y la razón que nos impulsó a limitamos sólo a la Suma de Teología en un análisis que pretende ser textual, minucioso y por lo mismo tal vez un poco tedioso.

La elección de Tomás de Aquino obedece al lugar central que este pensador ocupa no sólo en el medievo sino en toda la tradición teológica posterior. La resistencia que encuentra en su momento de parte de una tradición cerrada y de una religiosidad virulenta, ${ }^{4}$ llaman la atención e invitan a adentrarnos en la comprensión de la empresa por él acometida. ${ }^{6}$

De las múltiples obras de Tomás de Aquino, ninguna mejor que la Suma de Teología para brindarnos la originalidad de su pensamiento. No cabe duda de que el recurso a los otros escritos tiene su importancia y son una necesidad incluso para la comprensión misma de la Suma de Teología. Sin embargo, la ventaja que ofrece la Suma es la de presentarnos la doctrina tratada secundum ordinem disciplinae. ${ }^{6}$ Es una construcción, una sintesis personal en la que la concatenación misma de las cuestiones preanuncia el modo de captar y de abordar los problemas.

No nos detendremos en la consideración del tema complejo del "ordo disciplinae", ' sino que abordaremos de lleno la cuestión que nos ocupa a partir del estudio de cómo "las creaturas proceden de Dios" y dentro de él cuál es el lugar que le concierne al hombre en el hecho de la creación y en la condición original anterior al pecado.

La consideración de la producción del hombre, que de hecho integra la segunda parte del tratado del hombre en su perfección, completa el estudio del Hexameron bíblico interrumpido en la q. 74. Con el título genérico de De prima hominis productione, Tomás abarca todo el conjunto de problemas tradicionalmente tratados en los de hominis opificio de su tiempo. El prólogo de la q. 90 nos brinda el plan de conjunto:

"Después de lo establecido (la naturaleza humana), ahora hay que analizar el origen del hombre. Este asunto implica cuatro aspectos: 1) el origen del mismo hombre; 2) el objetivo; 3) de primer estado y condición del hombre; 4) su lugar."

4 Chenu habla de "une tradition resistante et d'une religion effarouchée", Chenu, Situation humaine, art. cit. p. 430. Cfr. E. Gilson, Pourquoi saint Thomas a critiqué saint Augustin, en Archive d'Histoire Doctrinale et Littéraire du Moyen Age, I(1926-1927)5-127. M. De Gandillac, Le platonisme au XII et au XIIle siècles, en Actes du Congres de Tours et de Poitiers, Paris, 1954. F. Ehrle, L'agostinismo e l'aristotelismo nella scolastica del secolo XIII, en Xenia Thomistica, 3(1925) 518-188. Para el estudioso así como para el aficionado son altamente sugerentes los capitulos segundo y tercero de Otto Herman Pesch, Tomás de Aquino. Limite y grandeza de una teologia medieval, Herder, Barcelona, 1992.

5 Este interés, ¿tal vez lo aliente alguna faceta contestataria? Desde el punto de vista de un teólogo "luterano", ver Pesch, Tomás de Aquino, op. cit. p. 19-51.

6 I Pars, prol., S. Thomas Aquinatis, Summa Theologiae, Biblioteca de Autores Cristianos, Madrid, 1951. Por lo general utilizaremos la traducción publicada por la misma editorial en su "editio maior" en cinco tomos en Madrid, 1994, con importantes comentarios y notas.

7 Además de Chenu, Introduction à l'étude..., ya citado.Ver $G$. Lafont, Structures et méthodes dans la Somme Théologique de saint Thomas d'Aquin, Paris-Bruges, Desclée de Brouwer, 1960. Pesch, Tomás de Aquino, op. cit. p. 455-477.

B El Tratado del hombre en la Suma de Teología va de la q. 75 a la q. 102 en las que se trata de la creación del hombre y de su vida en el estado originario. 
El abordaje de estos temas, como lo veremos mejor luego, está en estrecha dependencia de la historia de los orígenes tal como nos la propone la Escritura interpretada literalmente. Conviene, sin embargo, señalar que la prioridad otorgada a la causa eficiente sobre la causa final conviene al orden de las causas según el modo como entran en juego en el momento de la producción del que se excluye la consideración del pecado original tratado en la Secunda Pars.

Los amplios desarrollos consagrados por Tomás al estado y a la condición original del hombre se justifican ampliamente dentro del esquema de las "Procesiones" de las creaturas: es una afirmación de la bondad de Dios y de su creación. Los artículos dedicados al paraíso terrenal tienen un valor secundario y no ofrecen nada relevante a los fines de nuestra indagación.

Del programa trazado en el prólogo de la q. 90 nos detendremos sólo en los tres primeros ítems notando que no todos tienen igual importancia con relación a nuestro propósito. Aunque no encontremos consideración alguna ni referencia explícita sobre la corporalidad, intentaremos, con todo, vislumbrar el significado del cuerpo primero en la consideración de su producción, luego en aquella de la imagen de Dios en el hombre y finalmente en lo atinente a la condición corpórea en el estado de justicia original.

\section{La creación del hombre}

Antes de abordar el estudio de la producción del cuerpo, Santo Tomás trata de la producción del alma (q. 90). En esta primera cuestión sólo nos conciernen algunas observaciones del último artículo (Art. 4).

A la pregunta si el alma humana fue creada antes del cuerpo, sigue una respuesta negativa en la que engloba no sólo el rechazo del pre-existencialismo de Orígenes y de Agustín sino también la suerte misma del alma. Está en juego la concepción del hombre. Sin desautorizar abiertamente la postura de Agustín y apoyándose en lo logrado en las cuestiones 75 y 76, Tomás afirma sin ambages que el alma no fue creada antes del cuerpo. ${ }^{9}$

La respuesta a la primera dificultad retoma en otras palabras la misma afirmación y concluye con una expresión que responde las Objeciones de la cuestión: el alma "naturalmente es la forma del cuerpo" de modo que no sería creada separadamente "sino en él". ${ }^{10}$

La consideración de la producción del cuerpo del primer hombre (q. 91) comienza con un articulo cuya argumentación depende directamente del texto de Gn 2, 7: "El primer hombre ¿fue o no fue hecho del barro?"." La interpretación literal de dicho texto se hace con total recurrencia a la concepción de la física y cosmología de entonces.

9 I, q. 90 , a. 4, c. Anima autem, cum sit pars humanae naturae, non habet naturalem perfectionem nisi quod est corpori unita. Cfr. I, q. 91, a. $4,3^{\text {ta }}$ y $5^{\text {ta }}$.

10 I, q. 90, a. 4, 1ra "Sed quia naturaliter est forma corporis, non fuit seorsum creanda, sed debuit crear in corpore. En el Sed contra leemos: "Cum ergo anima sit proprius actus corporis, anima producta est in corpore". Las cuestiones consagradas a la naturaleza y psicologia del hombre tienen una importancia decisiva, cfr. O. 75-89.

11

I, q. 91 a. 1. El modo de conocer del hombre está estrechamente ligado a su modo de ser, por eso los elementos están equilibrados y en una armonía perfecta. 
El cuerpo del artículo, sin embargo, se sitúa de lleno en la óptica teológica resumiendo en cierto sentido la totalidad de la cuestión en una perspectiva amplia y dinámica $^{12}$ que sugiere una teología de la creación que, a pesar del interés despertado, no podemos comentar aqui..$^{13}$ Observemos sólo, por el momento, que la creación del cuerpo del primer hombre es considerada como participación de la perfección divina, participación ordenada conforme a una jerarquía en la que cada ser tiene todo lo necesario para realizar su perfección. El hombre, ser intermedio entre el mundo espiritual y el mundo corporal, se distingue del ángel - es inferior a él por el limite que representa su modo de conocer - y está por encima del mundo material, reasumiéndolo en sí de cierta manera, por su alma. A ello "se debe que el hombre sea llamado 'mundo en pequeño' (microcosmos)". ${ }^{14}$

De la afirmación del hecho de la creación del cuerpo del primer hombre no se sigue necesariamente la indicación del modo. Aún cuando admita en el art. 2 una acción formadora a partir de la materia pre-existente (barro del suelo), se habla de la creación inmediata del cuerpo del primer hombre. De este modo se excluye, por una parte, la mediación de cualquier suerte de potencia creada, retomando la argumentación apoyada en el hilemorfismo aristotélico ya empleada en la consideración de las creaturas corpóreas en general ${ }^{15} \mathrm{y}$, por otra parte, la existencia de cualquier forma material preliminar. En oposición, la 4ta. objeción invoca la autoridad de Agustín y su doctrina de las razones causales. La distinción elaborada en la respuesta permite obviar la objeción, salvaguardar la autoridad de Agustín y, luego, servir para probar la creación inmediata del cuerpo de la primera mujer. ${ }^{16}$

El art. 3 añade mayores precisiones respecto a la producción del primer hombre. Al preguntarse sobre la disposición otorgada al cuerpo en dicha producción, se podrá poner en relieve una vez más la perfección de la obra de Dios manifiesta en el cuerpo del hombre. ${ }^{17}$ El poder de Dios es ordenado: da con generosidad pero teniendo en cuenta el fin propio de cada ser. Ahora bien, puesto que la materia se ordena a la forma así como los instrumentos a la acción del agente, de igual modo el fin próximo del alma es el alma racional y sus operaciones. De ahí quie se pueda concluir sin equívocos: "Decimos que Dios hizo el cuerpo humano en la mejor disposición para tal forma y operaciones. Si parece que hay algún defecto, hay que tener presente que se trata de una consecuencia necesaria de la misma materia que se precisa para que se dé la debida proporción entre el cuerpo y el alma y sus operaciones del alma".

12 I,q. 91, a. l. c. Sobre la influencia del Pseudo Dionisio cfr. E. Gilson, Le Thomisme. Introduction à la philosophie de saint Thomas d'Aquin, $5^{\circ}$ ed., revue et augmentée, Paris, Vrin 1947. p. 196-206. En la pagina 197 tal vez convenga leer Proclo y no Plotino. Ver B. Romeyer, art. Denys le PseudoAeropagite, II. - L'aeropagitisme, dans Catholicisme, t. 3, col 622.

Ver Gilson, Le thomisme, op. cit. p.182-186. Pesch, Tomás de Aquino, op. cit. 471-477.

I, q. 91, a. 1., c. Cfr. I, q. 94, a. 4, It; I-II, q.77, a. 8, c.

I, q. 65 , a. 4 ; q. 45 , a. 8 ; q. 90 , a. 2.

I. q. 91 , a. 2, c. y $4^{4}$. Sobre la creación inmediata el cuerpo de la mujer I, q. 92, a. 4. La creación inmediata del cuerpo del hombre a partir de una materia preexistente se emplea para probar la creación de la mujer a partir del hombre I, q. 92 , a. $2,2^{\text {da }}$; q. 92 , a. 4 , c y $2^{\text {da }}$. Para un comentario serio y agudo sobre la mujer en el pensamiento tomasiano ver "Digresión" en Pesch, Tomás de Aquino, p. 246-269. cfr. I, q. 91, a. 1, $1^{\text {to }}$.

1. I, q. 91, a. 3, c. En las respuestas a las objeciones se ilustra, conforme a los conocimientos físicos y psicológicos de la época, el perfecto ordenamiento del cuerpo al alma. 


\section{El cuerpo ¿“imagen" o "vestigio"?}

Como lo manifiesta el prólogo de la q. 93, la consideración del fin de la producción del hombre está polarizada por el texto de Gn 1, 26: "el hombre fue hecho a imagen y semejanza de Dios". ${ }^{19}$

Las palabras de la Escritura, latentes en esta especificación del prólogo, son interpretadas conforme a las enseñanzas de Agustín pero desde una perspectiva directamente influenciada por el realismo de la psicología aristotélica y por una concepción del universo de inspiración neoplatónica. ${ }^{20}$

La importancia de estos desarrollos que conducen al reconocimiento de la "imagen" como fin de la producción del hombre no necesita demostración alguna. Es suficiente con que tengamos presente, aun sin profundizar demasiado, la importancia primordial del fin en el sistema de causas. ${ }^{21}$ Nuestro objetivo no es desarrollar el tema en toda su amplitud sino, como ya lo hemos precisado, nos preocupa sólo determinar el lugar y el valor que Tomás otorga y reconoce al cuerpo del hombre en la finalidad de su producción.

(a) Luego de haber desglosado los requisitos de la imagen perfecta y de poner de relieve, conforme con la Escritura, que en el hombre existe cierta semejanza, una imagen imperfecta de Dios por el hecho de la creación, ${ }^{22}$ Tomás se apresta a elaborar una noción muy precisa de imagen de Dios en las creaturas. Dentro del género semejanza se sitúa la cualidad de imagen denotando una semejanza específica, semejanza que se considera por ello a nivel de la diferencia última. De inmediato dicha noción será empleada para probar, con el apoyo de Agustín, que "solo las criaturas intelectuales son propiamente hablando imagen de Dios". ${ }^{23}$

Esta determinación del concepto de imagen no excluye una cierta participación en ella de los seres carentes de inteligencia ya que todo efecto es de alguna forma proporcionado a la causa. Podremos hablar de imagen pero no en sentido estricto. ${ }^{24}$ La respuesta a la primera Objeción, respetuosa de la autoridad de Dionisio, nos retrotrae a lo enseñado a propósito de la consideración sobre la emanación del ser. ${ }^{25} \mathrm{La}$ conclusión del artículo y las nociones de imagen y de vestigio clarificadas aquí serán empleadas nuevamente develando sus implicancias en el momento de evidenciar en qué consiste en el hombre realmente la imagen de Dios.

19 I. q. 93, prol. "Deinde considerandum est de fine sive termino productionis hominis, prout dicitur factus ad imaginem et similitudinem Dei" El texto de Gn 1, 26 se cita directamente en I, q. 93, a. 1, Sed Contra.

20

M.-J., De Beaureceuil, L'homme image de Dieu selon saint Thomas, en Etudes et Recherches 8 (1925)45-82 y 9(1955) 37-96. Sobre la influencia del Pseudo-Dionisio ver supra nota 12 y J. Turbessi, Denys le Pseudo-Aeropagite, V. - Influence du Pseudo-Denys en Occident, 3. Saint Thomas, en Catholicisme, t. 3, col 349-356

21

Cfr. I, q. 5, a. 4, Sed Contra; I-II, q. 1, a. 2, c. No olvidemos el axioma "Finis est causa causarum". Cfr. De Beaureceuil l'homme image de Dieu, art. cit. $2^{\text {de }}$ P., p. 50-59.

22

I, q. 93, a. 1. Este artículo expone las condiciones de la noción de imagen que se aplicaran luego. En el art. 4 se señalan tres modos de realización de la imagen. Cfr. De Beaureceuil, L'homme image de Dieu, art. cit., P. I, p.73.

23 I, q. 93, a. 2, c. El subrayado es nuestro.

${ }^{24}$ I, q. 93, a. 2, 1ra. la 2da señala que la imagen se sitúa en el ámbito de la naturaleza y por lo tanto se excluye una interpretación simplemente metafórica. Cf. $4^{\text {ts }}$, de Beaureceuil, L'homme image, art. cit., P. I, p. 72-73.

25

I, q. 45 , a. 7 , c. 
El articulo 6, en efecto, enfrenta de lleno la cuestión sobre qué constituye la imagen de Dios en el hombre utilizando una argumentación que supera generosamente los requisitos de tal determinación. A partir del hecho que en toda creatura existe una cierta semejanza de Dios, la argumentación se abre con las nociones de imagen y de vestigio elaboradas en el art. $2{ }^{26}$

La reflexión avanza hacia la determinación de lo constitutivo de la imagen de Dios en la creatura espiritual como tal. De ahí que una vez establecida la diferencia última entre las creaturas dotadas de razón de las que no lo son, es posible concluir: "que tampoco en la criatura racional se encuentra la imagen de Dios a no ser según la mente. En las demás partes de la criatura racional se encuentra la semejanza de vestigio, como en las demás cosas a las cuales se asemeja por tales partes". ${ }^{27}$ Y no puede ser de otra manera del momento que entendemos por imagen una semejanza específica, mientras que el concepto de vestigio designa una representación de la causa que no logra la semejanza especifica: tales las huellas que dejan los animales, la ceniza que deja el fuego, la desolación que deja un ejercito enemigo. ${ }^{2 B}$

Acto seguido dichas nociones son ampliadas considerando cómo las creaturas dotadas de razón denotan una semejanza especifica de la naturaleza divina y de la Trinidad increada, mientras que las demás propiamente se limitan a evidenciar semejanzas generales: sólo reflejan la causa que las produjo. En la ultima frase, con la fuerza de una conclusión, retoma el caso del hombre: "Así, pues, en el hombre se encuentra la semejanza de Dios como imagen en cuanto a la mente y como vestigio en sus otras partes". ${ }^{29}$

Nos detuvimos en este articulo por la importancia que tiene en la antropología de la Suma de Teología. De manera general se trata en él de la imagen de Dios en el hombre, aunque desde una perspectiva particular. Lo que el Génesis refiere al hombre, creados "hombre y mujer", Tomás continuando una larga tradición, lo aplica al ángel y al hombre ${ }^{30}$ considerados dentro de una jerarquía de creaturas. ${ }^{31}$ Por esta razón la argumentación el cuerpo del articulo incluye a todos los seres dotados de razón en los que se encuentra impresa la imagen de Dios ${ }^{32}$ distinguiéndolos del mundo material, signo esplendoroso de la acción de Dios. Con

26 "Cum in omnibus creaturis sit aliqualis Dei similitudo, in sola creatura rationali invenitur similitudo Dei per modum imaginis, ut supra dictum est; in aliis autem creaturis per modum vestigii" I, q. 93, a. $6, \mathrm{c}$.

q. 93, a. 6, c.

I, q. 93, a. 6, c.

I, q. 93, a. 6, c. Cf. I, q. 3, a. 1, $2^{\text {das. }}$ Y luego aclara: "Quod tamen non sit intelligendum, quasi in corpore hominis sit imago Dei; sed quia ipsa figura humani corporis repraesentat imaginem Dei in anima, per modum vestigii" I, q. 93, a. 6, 3ra. Sobre la noción genérica de semejanza y lo que en ella se contiene. I, q. 93, a. 9, c. Sobre la incidencia de estas cuestiones en la teologia de la justificación, ver Pesch, Tomás de Aquino, op. cit., p. 457-462.

I, q. 93, a. 3: "Ultrum angelus sit magis ad imaginem Dei quam homo". La conclusion es tan matizada cuanto firme: "Et ideo, cum quantum ad intellectualem naturam angelus sit magis ad imaginem Dei quam homo, simpliciter concedendum est angelum magis esse ad imaginem Dei; hominem autem secundum quid" I, q. 93, a. 3, c. Por lo que respecta a la mujer, cf. I, q. 93, a. 6, $2^{*}$ y $2^{\text {da }}$. De Beaureceuil, $L$ 'homme image, art. cit. P. 2, p 59-72.

Cf. I, q. 93 , a. $6,1^{\text {th }}$. 
todo, el cuerpo del hombre ocupa un lugar muy particular en el ámbito de vestigio: "la misma figura del hombre es un huella que representa la imagen de Dios en el alma", ${ }^{33}$ o sea, es signo de la condición y vocación espiritual del hombre.

(b) Sin embargo, todo lo dicho no hace justicia al contenido de este articulo en la Suma de Teología, especialmente en lo que atañe a la consideración del hombre en su naturaleza. Cabe, por lo tanto, preguntarse qué se entiende por mens (alma) y si acaso existe alguna relación entre los dos primeros capítulos de su antropología que serán los estudiados por el momento.

$\mathrm{El}$ art. 6 de la q. 93 no nos da ninguna pauta sobre el vocabulario, aún cuando el vocablo mens aparezca más a menudo que en los otros artículos. ${ }^{34}$ Sin embargo, una vez más será la respuesta a una objeción lo que nos permitirá determinar el contenido del vocablo. Invocando la autoridad de S. Pablo, la objeción sostiene que la imagen de Dios no se cumple sólo en el alma espiritual del hombre porque "el varón no es sólo mente" ${ }^{35}$ La respuesta establece una distinción que le permite concluir que existe la imagen de Dios en el hombre aún cuando ésta no se, verifique en todas y un cada una de sus partes, "El hombre es imagen de Dios, no en cuanto que él mismo sea esencialmente imagen, sino en cuanto que en él está la imagen de Dios impresa en su mente" ${ }^{36}$

Esta distinción entre la esencia del alma y sus facultades fue formulada anteriormente en el estudio de la psicología humana. Dicha distinción es propia del hombre, como de toda creatura, porque "solo en Dios entender es lo mismo que ser ${ }^{n}{ }^{37}$ Por esta misma razón, aunque la inteligencia sea llamada alma (mens), no se sigue que deba entenderse por entendimiento la esencia del alma a pesar que Agustín hable del entendimiento (mens) como esencia del alma. Sólo indica de esa manera la principal facultad del alma, la parte más noble del hombre, así como se designa al alma intelectiva por "entendimiento". ${ }^{3}$

La imagen de Dios se encuentra en lo mejor del hombre, en la mens, que designa una facultad del alma, vale decir, el alma en tanto dotada de inteligencia y voluntad. Pero puede entenderse también por mens la esencia del alma en cuanto todas las facultades se originan en ella. ${ }^{39}$ Conviene señalar que la noción de mens no implica la corporalidad ni directa ni indirectamente. Concieme sólo a la inteligencia y a la voluntad en sus funciones propias con total independencia del cualquier órgano corporal. ${ }^{40}$

33

अ

36

37

38

39

40

Cf. I, q. 93 , a. $6,3^{\text {ra }}$.

La Palabra mens aparece: 3 veces en el art. 2; 1 vez en los arts. 3 y 4; 13 veces en el art. 6 (del que hablaremos); 11 veces en el art. 7; 10 veces en el art. 8; $y$ una sola vez en el art. 9.

I, q. 93 , a. $6,1^{\text {ta }}$.

I, q. 93, a. $6,1^{\text {ta }}$. Sobre el ejemplo con la efigie de César cf. I, q. 93, a.1, $2^{\text {da }}$; sobre los requisitos de la imagen perfecta I, q. 93, a. 1, c y supra nota 22 .

I, q. 79, a. 1, c. "Unde in solo Deo intellectus est eius essentia, in aliis autem creaturis intellectualibus intellectus est quaedam potentia intelligentis".

I, q. 79 , a. $1,1^{*}$ y $1^{\text {ti }}$; cf. I, q. 75 , a. 4 , Im.

H. D. Gardeil, Les origines de l'homme, Ia, questions 90-102, notes et appendices, en Saint Thomas d'Aquin, Somme Thélogique, Paris, Cerf, 1963, nota 58, p. 312-313. De Beaureceuil, L'homme image, art. cit. P. I, p. 75-75.

"Unde manifestum est, quod omnes potentiae animae, sive subiectum earum sit anima sola, sive compositum, fluunt ab essentia animae sicut a principio q. 77, a. 6, c. En los otros art. de la q. 77 se 
La referencia al primer capitulo de la antropologia de la Prima Pars sugiere na continuidad que, en realidad, tiene raíces muy profundas. Sin intentar siquiera ssbozar el tema, digamos al menos que, justamente en este articulo de la q. 93 ;obre la imagen de Dios en el hombre, la determinación del prólogo de la q. 75 nanifiesta su motivación profunda: "Al teólogo le corresponde estudiar la naturaeza humana en lo referente al alma, no en lo referente al cuerpo, a no ser en cuinto está en relación con el alma". ${ }^{41}$ Con lo dicho ilustramos adecuadamente lo leterminante que es en estos capítulos de la antropología de Tomás la considerasión del fin del hombre, de su retorno a Dios (150). ${ }^{42}$

\section{La condición original}

El prólogo de la q. 94 nos introduce en el tema señalando que el tratamiento de lo referente al estado o condición del primer hombre se hará en dos etapas: srimero lo referente al alma, después al cuerpo..$^{43} \mathrm{La}$ división de los temas en su detalle apunta a proyectar la reflexión más allá del caso Adán. Al estudiar lo relativo a la conservación no sólo del individuo sino también de la especie se posibilita la consideración de la descendencia de Adán en el estado de inocencia. ${ }^{4}$ Este aparente desplazamiento sobre lo anunciado en el prólogo de la q. 94 no es accidental. ${ }^{45}$ Para dar cuenta de ello habrá que tener en vista la problemática de estos temas en el siglo XIII, en una manera de pensar cercana al texto de la Escritura entendido literalmente, por una parte, y por otra - y esto es muy importante - en la estructura y el método mismo de la Suma de Teología.

insiste sobre lo mismo, pero las bases fueron puestas en I, q. 75, a. 4 c; Cf. q. 75, a. 3, c.; y las Soluciones de los arts. $3,4,6$ y 7 de la q. 84 .

I, q. 75 , prólogo.

42 De Beaureceuil, L'homme image, art. cit. se plantea el problema de la continuidad entre los dos capitulos de la antropologia de la I Pars y señala que "L'anthropologie aristotélicienne de S. Thomas, selon laquelle le corps est partie essentielle de l'homme, aurait dû le pousser à lui donner place dans sa doctrine de l'image" (P. II, p. 70). Responde distinguiendo entre el punto de vista del filósofo y el del teólogo cf. Ibid. p. 71-72. Nos inclinariamos a pensar que habría que analizar la cuestión con mayor precisión y en un contexto más amplio. Por ejemplo, habria que determinar, en lo que concierne al realismo aristotélico, si el mismo Aristóteles fue siempre consecuente con él, cosa que parece no ser cierta. Ver P. Daubercies, La condition chamelle. Recherches positives sur la théologie d'une réalité terrestre, Tournai, Desciée, 1959, p. 116-131. Para ser más exactos, habria que hacer ese estudio en el Aristóteles latino utilizado por Tomás, considerando que en el siglo XIII no se tenía conciencia de la evolución del pensamiento de Aristóteles. Santo Tomás mismo toma la obra de Aristóteles como un todo, pero sabe moverse, ver Chenu, Introduction à l'étude, op. cit., pp. 129-131. Sobre la importancia de la interpretación histórico - genética, ver C. Solari, Aristotele e S. Tommaso. Osservazioni sulle concessioni dell'anima e dell'etica nei due pensatori, en Rivista di Filosofia Neo Scolastica 51 (1959) 193-227, particularmente pp. 200; 209-210. Finalmente habria que determinar si existe o no parentesco entre la visión jerárquica de inspiración neoplatónica y el aristotelismo, cf. I. O. 76, A. 3, c. Y la nota 33 del comentario en J. Webert, L'âme humaine, Ia, Questions 75-83, en S. Thomás d'Aquin, Somme Théologique, Paris, Desclée \& Cie,1928.

43 "Deinde considerandum est de statu vel conditione primi hominis. Et primo quantum ad animam; secundo, quantum ad corpus" I, q. 94, pról.

44 Los prólogos de las q. 97, 98 y 99 se escalonan por orden progresivo.

45 Comparar I, q. 90, pról. con q. 94, pról. 
Conviene dejar de constancia que todos estos artículos se rigen por un principio expresamente formulado en el art. 2 de la q. 98: "Lo que es natural en el hombre ni se le añade ni se la retira por el pecado" ${ }^{46}$ principio clave que no sólo anuncia ya la futura concepción teológica del pecado, sino que, a la vez, sienta un precedente teológico que, en su originalidad, fue totalmente soslayado por la teología de su tiempo y la posterior."

En nuestra indagación procederemos de modo sintético reagrupando en tomo de algunos temas centrales todos los contenidos dispersos en estas ocho cuestiones. En primera instancia nos preguntaremos por el lugar y valor del cuerpo para luego considerar lo referido a la delectación sensible en la condición primera del hombre.

(a) Una vez más nuestra investigación sobre el cuerpo deberá iniciarse con el análisis de lo referente al alma. El art. 2 de la q.94 nos brinda una respuesta directa y sin equívocos. A la pregunta de si Adán en el estado de inocencia veía los ángeles según su esencia, sigue una respuesta negativa. La razón, enunciada sintéticamente por el silogismo del Sed Contra, ${ }^{48}$ se aplica y desarrolla en el cuerpo del articulo donde la argumentación gira en torno del hecho que "el alma humana en el estado de inocencia era apta para perfeccionar y regir el cuerpo como ahora" ${ }^{49}$ Establecido el punto de partida, no queda sino integrar las adquisiciones del estudio metafísico del hombre: "polque la operación intelectual del alma se ordena naturalmente a lo externo", ${ }^{50}$ realidad posible a partir del momento que al alma "apta para regir y perfeccionar al cuerpo en su vida animal, le corresponde conocer recurriendo a las imágenes". ${ }^{.1}$

Encontraremos la misma argumentación una vez más en lo referente a las prerrogativas del cuerpo del hombre en su estado primero. ${ }^{62}$ El principio: "Lo que es natural en el hombre ni se le añade ni se le retira por el pecado" adoptará formas diversas según los distintos contextos, pero estará siempre vigente como respetuosa referencia a la realidad concreta en un ámbito en el que la tentación de dejarse llevar por la imaginación es demasiado fuerte. ${ }^{50}$

46 "Ea enim quae sunt naturalia homini, neque subtrahuuntur neque dantur homini per peccatum". Cf. También I, q. 96, a. 3. c; q. 100, a. 1, c; q. 101, a. 1, Sed contra. El pecado no cambió la naturaleza de los animales: I, q. 96 , a. 1, y $2^{\text {da }}$; q. P6, a. 2. c. Ver, Pesch, Tomás de Aquino, op. cit., p. 230-256. El artículo responde a la cuestión "utrum Adam in statu innocentiae angelos per essentiam viderit" I, q. 94 , a. 2 , Sed contra y $2^{\text {da }}$. I, q. 94, a. 2, c. "Anima enim hominis in statu innocentiae erat corpori perficiendo et gubemando accomodata sicut et nunc". El subrayado es nuestro.

50 I, q. 94, a. 2, c. conclusión que se apoya en I, q. 87, a. 3, c.

${ }_{11}$ I, q. 94, a. 2, c. La argumentación de este artículo supone claramente I, q. 84, a. 7; q. 85, a. l; q. 89, a. 1. La respuesta a la $2^{\text {da }}$ de la q. 94, a. 2 es sólo una aplicación. En el mismo sentido: I, q. 101, a. 1, c.; q. 101, a. 2, c y $1^{\text {ra }}$.

62 Hablamos de "estado primero u original" y no de "primer hombre" porque estos desarrollos se aplican tanto a Adán como a su descendencia en el caso que no hubiese existido pecado.

53 La generación humana se hubiese realizado por la unión del hombre y de la mujer: I, q. 98, a. 2, c. Los hijos de Adán hubiesen crecido y se hubiesen desarrollado: I, q. 99, a. 1, c. Sobre el principio básico ver B. Quelquejeu, "Naturalia manent integra" Contribution à l'étude de la porté méthodologique et doctrinale de l'axiome théologique "gratia praesupponit naturam", en Révue des Sciences Philosophiques et Théologiques 49(1965)640-655. 
La aplicación de este principio suministra un punto de apoyo sólido en el momento de determinar las relaciones del alma y del cuerpo en el estado de inocencia. Siguiendo a Agustín, ${ }^{54}$ y con referencia a un texto del Eclesiastés, ${ }^{55}$ la rectitud del estado primero consistía en la sumisión de la voluntad a Dios, de las fuerzas inferiores a la razón, del cuerpo al alma ${ }^{56} \mathrm{Y}$ aclara inmediatamente "Pero es evidente que este sometimiento del cuerpo al alma y de las facultades inferiores a la razón no era natural. De serlo hubiera permanecido después del pecado, pues los dones naturales, como dice Dionisio en c. 4 De Div. Nom, permanecieron en los demonios. Por eso es evidente que el primer sometimiento, por el que la razón se subordina a Dios, no era sólo natural, sino un don sobrenatural de la gracia, pues el efecto no puede ser superior a la causa". ${ }^{57}$

Dicha sumisión sobrenatural de la razón a Dios es el fundamento de las prerrogativas propias del cuerpo en el estado de inocencia, privilegios que, sin embargo no eximían totalmente de las leyes de la naturaleza. ${ }^{58}$ La sumisión de las facultades inferiores a la razón y del cuerpo al alma, consecuencia de la sumisión de ésta a Dios, habría permitido al hombre librarse de la corrupción de la muerte. ${ }^{50}$

En razón de dicha sumisión y con relación a este primer privilegio, el hombre en el estado original gozaba de otro: el de la impasibilidad. Esta prerrogativa, a su vez, no implicaba ningún menoscabo para el legítimo uso de los sentidos.

A tal efecto, en la q. 97 se distinguen dos sentidos de la palabra pasión (passio). El primer sentido, el propio, indica "cuando algo es sacado de su disposición natural", mientras que en el sentido corriente, pasión (passio) "es cualquier mutación incluso la que perfecciona la naturaleza". ${ }^{80}$

El hombre era impasible sólo en este primer sentido, puesto que en el segundo modo el hombre, en el estado de inocencia, era pasible y padecía a la vez en su alma y en su cuerpo ${ }^{61}$ ya que dicha pasión se ordenaba al bien de la naturaleza.

${ }^{54}$ H. Rondet, L'anthropologie réligieuse de saint Agustin, en Recherches; de Sciences Réligieuses 29(1939) ver p. $165-167$.

"Deus fecit hominem rectum"Eccl. 7, 29. Excepto I. q. 91, a. 3 Sed Contra, donde por "rectum" se alude a la perfección propia del hombre, todas las demás referencias a este texto escriturístico se sitúan en continuidad con Agustin: por "rectum" se entiende la perfecta sumisión del cuerpo al alma resultante de la sumisión del alma de Dios: I, q. 94, a. 1, c; q. 95, a. 1, c.; q. 99, a. 1, c. Lo propio del estado de inocencia es la sumisión del cuerpo al alma, por gracia. A las referencias de la nota anterior, añadir, I, q. 94 , a. 2, c.; q. 94 , a. 4c; q. 95, a.2; q.95, a. 3 c; q. 98 , a. 2 , c. I, q. 95 , a. 1, c. Cf. I, q. 100 , a. 1, $2^{\text {da }}$.

58 Esta sumisión excluia toda suerte de mal: I, q. 94, a. 4, c; podían conocer las cosas naturalmente cognoscibles con mayor facilidad: I, q. 94, a. 3, 3ra; fue hecho para instruir y gobernar I, q. 9, a. 3, c; siendo su cuerpo vigoroso no hubiese necesitado de los animales: I, q. 96, a. l, 3ra; la sumisión del cuerpo al alma le hubiese permitido determinar el sexo de los hijos I. 99, a. 2, 2da puesto que hubiese existido generación: q. 98, a. 1. Sin embargo existirian desigualdades tanto en el alma como en el cuerpo, "pues (el cuerpo) no era ajeno a las leyes naturales" I, q. 96, a. 3, c. I, q. 97, a. 1, c. Cf. I, q. 90, a. 4, $3^{\text {m}} ; 97$, a 4, c: el Arbol de la Vida hubiese contribuido a prolongar la vida del hombre y, tal vez de alguna manera, a hacerlo inmortal; q. 102, a. 2, c. 
A pesar de todos estos privilegios, la vida del hombre en el Paraíso no era más que una vida "animal". ${ }^{62} \mathrm{La}$ incorruptibilidad de la que gozaba el cuerpo se debía al alma, gracias a una fuerza sobrenatural, el cuerpo, en cuanto tal, seguía siendo mortal. Esta situación era perfectamente normal ya que la perfección original no es todavía la perfección definitiva, la de la gloria. ${ }^{63}$

En este contexto Tomás utiliza un vocabulario de manifiesta inspiración paulina precisándolo cuidadosamente para evitar malos entendidos. En primer lugar señala que Adán, por el hecho de su creación en gracia, era un ser espiritual en su alma, pero "no fue espiritual en cuanto al cuerpo" porque la vida espiritual del cuerpo "empezó en Cristo" ${ }^{\text {e4 }}$ Este mismo vocabulario será retomado luego de un desarrollo más amplio: "[...] alma racional es alma y espíritu. Se dice que es alma por lo que tiene de común con la de los animales, dar la vida al cuerpo [...]. Pero es también espíritu por lo que tiene de propio y no común con los animales, esto es, su potencia intelectiva inmaterial" ${ }^{65}$

(b) En lo concerniente a la delectación sensible el material es menos abundante. Lo que encontramos, dicho de paso y en estrecha relación con los principios que acabamos de analizar, preparan en cierta manera los desarrollos de la Secunda Pars. ${ }^{66}$ La sumisión de la razón a Dios, cuyo resultado es la sumisión de las facultades inferiores al alma, podría dar la impresión de la no-existencia de pasiones en el estado de inocencia. Este tema, de apariencias simples, involucra de manera directa el problema de la concepción de las pasiones y de los efectos del pecado en la naturaleza del hombre. ${ }^{\text {"7 }}$

Sobre el primer problema nos contentaremos con lo ya dicho. En lo que dice al segundo cabe dejar bien claro que en el estado de inocencia el hombre no era "impasible" sino con relación a las pasiones que entorpecen la razón. Las pasiones del alma en sí mismas no son por lo tanto malas. "Las pasiones del alma residen en el apetito sensitivo cuyo objeto es el bien y el mal" . Esta distinción de objetos permite concluir que existían pasiones sensibles en el estado de inocencia, Siempre ligadas a un juicio de la razón, dichas pasiones podían concernir un bien presente o un bien futuro. ${ }^{69}$ El placer sensible tenía cabida en el estado de inocencia y podríamos llegar a pensar que tal vez entonces tendría una mayor intensidad a partir del momento que la naturaleza era más pura y el cuerpo más sensible "Estas conclusiones fueron increíblemente innovadoras en

62 Ver notas anteriores 52, 57 Y 58. El paraíso era el Lugar de residencia del hombre durante el tiempo de su vida "animal"; el cielo es el de su vida "espiritual": I, q. 102, a. 4 c.

En I, q. 97, a. 1, en el que el texto de la autoridad es $\mathrm{Rm} 5,12$ : "Por el pecado entró la muerte en el cuerpo, Tomás distingue cuidadosamente las distintas incomuptibilidades. Ver la 4ta de este mismo artículo. Por lo que se refiere al cuerpo en la glonia, ver I-II, q. 4, la III Pars no fue concluida directamente por Tomás.

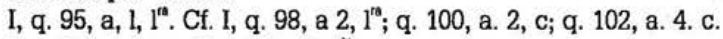
I, q. 97, a. 3, c; Cf. q.97, a.l, $4^{\text {th }}$.

Sobre la delectación ver I-II, q. 2, a. 6; q. 3, a. l; q. 3, a. 2: q. 4, arts. 1 y 2; q. 31 a q. 34.

Sobre la moralidad de las pasiones ver I-II, q. 24.

I, q. 95, a. 2, c. La argumentación opone nuestra situación a la del estado de inocencia. Ver también, I, q. 94 , a. 1 , c y $l^{\text {ta }}$ y $3^{\text {ts }}$; q. 95 , a. $2,2^{\text {ded }}$; q. 98 , a. 2 , c.

I, q. 95, a. 2 c. Sobre el ejercicio de la razón en el hombre en su condición primera y como frontera y línea de demarcación entre dos mundos ver i, q. 96, a. 2, c. 
su tiempo". ${ }^{70}$ A estas breves indicaciones sobre las pasiones deberiamos añadir las concernientes a las virtudes. Admitir en Adán la existencia de todas las virtudes presenta ciertas dificultades ya que algunas virtudes implican una imperfección incompatible con la perfección original. Sin adentrarnos en los detalles de la argumentación, señalemos que las virtudes de temperancia y de fuerza tenían su lugar.

Por una parte debemos afirmar que es accidental a la templanza y a la fuerza el refrenar las pasiones excesivas, en tanto que se dé tal exceso en el sujeto. Lo que le es propio es moderar las pasiones. ${ }^{n}$

Por otra parte las pasiones existían, como lo vimos, a tal punto que "podían darse en el estado primitivo los actos de templanza que moderan los placeres y los de fortaleza que moderan la audacia y la esperanza". ${ }^{n}$

Llegados al término de nuestra investigación sobre la significación del cuerpo del hombre y de la delectación sensible en algunos textos de la Prima Pars, podemos concluir que el misterio del hombre es estudiado en la sección consagrada a la creación y en la última parte del estudio del Hexameron bíblico. La exégesis bíblica sobre la producción del hombre, considerando su ajuste al texto y a la tradición, es, no obstante, continuamente apoyada por los resultados de estudio de la naturaleza del hombre que le precede (q. 75-89). El hombre se ubica dentro de una creación jerarquizada situándose en los confines del mundo espiritual por su alma y del mundo material por su cuerpo.

El problema de la finalidad de la creación parece constituir la preocupación central que ordena desde arriba toda problemática en la consideración de la creatura salida de Dios, vale decir, en todos los textos estudiados de la antropología de la Primera Pars. Este cuidado especial para encontrar en Dios el fin del hombre, al interior de una creación sintetizada en cierta manera por el hombre en su ser compuesto, parece explicar la determinación del prólogo de la q. 75. Por lo tanto, el hombre es considerado sobre todo en su dimensión espiritual.

Esta perspectiva particular y la importancia que tenia en el siglo XIII la cuestión de la unión del alma y del cuerpo (se trataba de integrar la materia en la naturaleza humana) en una metafísica en la que las condiciones concretas de los seres y de los fenómenos no se consideraban como objeto específico de conocimiento, son las razones principales del lugar secundario otorgado al cuerpo y a la delectación sensible. Sin embargo, aún cuando el problema de la corporeidad no sea jamás planteado, el hombre se sitúa para Tomás en el corazón del cosmos: es, en la unión fundamental de su ser, el punto de convergencia de la creación espiritual y material.

\footnotetext{
to I, q. 98, a. 2, $3^{\text {ta }}$. Se leerá con provecho el párrafo que Pesch titula "Las pequeñas victorias del Evangelio", en Tomás de Aquino, op. cit. p. 262-264.

71 I, q. 95 , a. $3,1^{\text {ra }}$.

72 I, q. 95 , a. $3,2^{\text {das. }}$
} 
El hombre es la obra de Dios que lleva en su alma la imagen del Creador y que manifiesta por su cuerpo, que en cierta manera deja transparentar el alma, el resplandor de la acción divina. Sin el alma, el cuerpo humano no es nada. Por el cuerpo, el alma se inserta profundamente en el mundo material de manera tal que el cuerpo llega a ser la expresión y la realización espacio-temporal del alma. Ésta, a pesar de su incorruptibilidad, tiene en lo profundo de sí una ordenación al cuerpo que transforma en situación anormal el estado de alma separada. En su necesidad del cuerpo para ser plenamente, el alma invoca la resurrección del cuerpo. En la patria, por Cristo, el hombre será espiritual tanto en su alma como en su cuerpo: en su cuerpo por su alma.

En esta breve incursión en la antropología de la Suma de Teología hemos podido sentir la unidad y la coherencia de una síntesis vigorosa y firme. Agustín, el Pseudo-Dionisio, Aristóteles tienen su influencia pero el resultado manifiesta la originalidad de un pensamiento personal: el de Tomás de Aquino. 